\title{
Feeding probiotic Lactobacillus rhamnosus (MTCC 5897) fermented milk to suckling mothers alleviates ovalbumin-induced allergic sensitisation in mice offspring
}

\author{
Vamshi Saliganti, Rajeev Kapila*, Rohit Sharma and Suman Kapila \\ Animal Biochemistry Division, National Dairy Research Institute, Karnal 132001, Haryana, India \\ (Submitted 22 January 2015 - Final revision received 16 June 2015 - Accepted 3 July 2015 - First published online 2 September 2015)
}

\section{Abstract}

The neonatal period is often polarised to T helper (Th2) response at the time of birth, predisposing offspring to allergic disorders. Passive immunity through the mother's milk is critical for immune system development of newborns. Probiotics have been proposed to harmonise Th1/Th2 imbalance in allergic conditions in adults. In the present study, the anti-allergic effects of feeding probiotic Lactobacillus rbamnosusfermented milk (PFM) either to dams during the suckling period or to their offspring after weaning individually or else in successive periods against ovalbumin (OVA)-induced allergy in newborns was analysed. After allergen sensitisation, physical symptoms of allergy, gut immune response, humoral immune response and cell-mediated response through interleukins were detected. Consumption of PFM by mothers and offspring showed a reduction $(P<0.01)$ in physical allergic symptoms in newborns with an increase $(P<0.01)$ in the numbers of goblet and $\operatorname{IgA}+$ cells in the small intestine. Similarly, considerable $(P<0.001)$ decreases in OVA-specific antibodies (IgE, IgG, IgG1) and ratios of IgE/ IgG2a and IgG1/IgG2a in the sera of newborn mice were recorded. A decrease in IL- 4 and an increase in interferon- $\gamma$ levels further confirmed the shift from Th2 to Th1 pathway in PFM-fed mice. It is logical to conclude that the timing of PFM intervention in alleviating allergic symptoms is critical, which was found to be most effective when mothers were fed during the suckling period.

Key words: Lactobacilli: Suckling-weaning transition: Allergies: Humoral immune response

The prevalence of allergic diseases in newborns continues to increase worldwide $^{(1)}$. It has been estimated that about $1-2 \%$ of the population and up to $8 \%$ of children suffer from some type of IgE-mediated food allergy ${ }^{(2)}$. Eight types of foods are responsible for causing the majority of food allergies, which include foods of plant origin such as peanuts, tree nuts, wheat and soya together with allergens of animal origin including cows' milk, egg, fish and shellfish. The spectrum of food allergy symptoms may include flushing, urticaria, angio-oedema, laryngo-oedema, diarrhoea, nausea, vomiting, bronchospasm or hypotension. As there are no medical treatments currently available for curing food allergies, the best way to prevent unintended exposure to a food allergen is the complete avoidance of the offending food. For various reasons, such avoidance may not always be possible, and in certain instances impossible. Early infancy is a critical period for the development of immunological memory, where the $\mathrm{T}$ helper (Th) balance converts from the Th2-skewed immunity to Th1 cell-type response under the influence of genetic and environmental factors. Studies suggest that postnatal maturation of the immune system in atopic individuals is attenuated, and atopic infants show an imbalance in Th1/Th2 immune response by excessive IgE responses ${ }^{(3)}$.
Probiotic bacteria, defined as live microorganisms administered in adequate amounts that confer health benefits to the host $^{(4)}$, have been proclaimed as candidate factors for alleviating Th1/Th2 imbalance in various clinical disorders ${ }^{(5,6)}$ in a bacterial strain-specific manner ${ }^{(7,8)}$. However, information regarding the probiotic actions on food allergy during suckling-weaning transition is insufficient with contrasting results ${ }^{(9,10)}$ to recommend it strongly for prevention of this 'fatal phenomenon' in the early days of life. Furthermore, it is imminent that such approaches aimed at ameliorating Th1/Th2 imbalance during infancy might have a better possibility in alleviating allergic disorders in adults. Information regarding the effect of probiotics in alleviating Th2 skewness in offspring during suckling-weaning transition is not only scanty but also restricted to particular tissue type (serum and peripheral blood mononuclear cells $)^{(7,11,12)}$ and lacks a holistic approach by analysing changes in different branches of the immune system. Thus, the present study has been conducted with the aim to gain conclusive understanding of the underlying changes in allergen-sensitised offspring on feeding Lactobacillus rhamnosus (MTCC 5897) fermented milk to mothers and to offspring separately or successively during suckling-weaning transition as a preventive agent against Th2-associated allergic disorders.

\footnotetext{
Abbreviations: cfu, colony-forming units; COX-2, cyclo-oxygenase-2; IFN- $\boldsymbol{\gamma}$, interferon- $\boldsymbol{\gamma}$; PFM, probiotic fermented milk; TLR-2, toll-like receptor-2.
} 


\section{Methods}

\section{Micro-organisms and culture conditions}

The probiotic L. rhamnosus (MTCC 5897) used in the present study was isolated from household curd and has been characterised earlier for probiotic attributes and immunomodulatory features in ageing mice ${ }^{(13)}$. The culture was stored at $-80^{\circ} \mathrm{C}$ in de Man, Rogosa and Sharpe (MRS) broth supplemented with $20 \%$ (v/v) glycerol and was activated before use by subculturing twice in MRS broth for $18 \mathrm{~h}$ at $37^{\circ} \mathrm{C}$. Probiotic fermented milk (PFM) was prepared by inoculating sterile skimmed milk with $1 \%$ of activated bacterial culture followed by incubation for $18 \mathrm{~h}$ at $37^{\circ} \mathrm{C}$ to obtain a final bacterial count of $1 \times 10^{9}$ colony-forming units $(\mathrm{cfu}) / \mathrm{ml}$. The number of bacteria in the fermented milk was determined by plate counting on MRS agar plates after aerobic incubation at $37^{\circ} \mathrm{C}$ for $24-48 \mathrm{~h}$

\section{Experimental design and feeding schedule}

Swiss albino mice (6-8 weeks old) weighing 25-31 g were maintained in the Small Animal House of the National Dairy Research Institute (NDRI). Male and female mice (1:2) were kept in polypropylene cages at room temperature under hygienic conditions; males were later removed from the cages after confirming pregnancy in females. All the procedures were approved by the Institutional Animal Ethics Committee (Approval letter no. NDRI 382/01CPCSEA; dated: 29 June 2011). Pregnant mice were fed semi-synthetic basal diet (18.4\% starch, $70 \%$ bengal gram (black chickpea) flour, $4.5 \%$ soyabean oil, $2 \cdot 1 \%$ mineral mixture, $1 \%$ vitamin mixture and $4 \%$ cellulose) up to parturition. The day of parturition was considered as day 0 of offspring life. The experimental mothers (seven dams) along with their suckling offspring (forty-two pups) were divided into three major groups (Fig. 1(a)) and fed basal diet (BD) $(5.0 \mathrm{~g} /$ mother per $\mathrm{d})$, BD supplemented with skimmed milk $(2.0 \mathrm{ml} /$ mother per d) and BD supplemented with PFM $\left(2.0 \times 10^{9} \mathrm{cfu} /\right.$ mother per $\mathrm{d}$ in $\left.2.0 \mathrm{ml} \mathrm{PFM}\right)$, respectively, during the suckling period for $20 \mathrm{~d}$. All the seven mothers were fed twice a day by dividing their total required diet into equal parts to ensure complete feed intake. On the day of weaning (day 21 after parturition), pups from the first group were separated and further divided into three subgroups of six pups each and fed BD, BD supplemented with skimmed milk (BD-MW) $(2.0 \mathrm{ml} /$ animal per $\mathrm{d})$ and PFM $\left(2 \cdot 0 \times 10^{9} \mathrm{cfu} /\right.$ animal per $\left.\mathrm{d}\right)$ followed with BD (BD-PW), respectively. Offspring of the second group in which mothers were fed BD supplemented with skimmed milk were also subdivided into two subgroups and were fed basal diet (BD-MS) and basal diet supplemented with skimmed milk (BD-MS + MW) $(2 \cdot 0 \mathrm{ml} /$ animal per d), respectively. Similarly, offspring from the third group in which mothers were maintained on BD supplemented with PFM were also divided into two subgroups and were fed basal diet (BD-PS) and PFM $\left(2.0 \times 10^{9} \mathrm{cfu} /\right.$ animal per d) followed with basal diet (BD-PS + $\mathrm{PW}$ ), respectively. Accordingly, there were four control groups, including one positive control (BD) where mothers as well as the offspring were fed basal diet alone and three delivery vehicle controls (BD-MW, BD-MS and BD-MS+MW) where skimmed milk was supplemented along with the basal diet. In case of the PFM groups (BD-PW, BD-PS and BD-PS + PW), basal diet was either supplemented with L. rhamnosus-fermented milk for suckling mothers or fed separately to weaned offspring before resumption to BD.

For feeding mothers during the suckling period, BD supplemented with skimmed milk or PFM were prepared by mixing their respective amounts $(4.0 \mathrm{ml}$ at $2 \mathrm{ml} /$ animal per $\mathrm{d}$ in $10 \mathrm{~g}$ at $5 \mathrm{~g} /$ animal per $\mathrm{d}$ ) in the basal diet of the particular group during preparation to the consistency of dough instead of water. Similarly, for the postweaning feed for offspring mice, the BD+skimmed milk diet was prepared by adding skimmed milk $(24.0 \mathrm{ml}$ at $2.0 \mathrm{ml} /$ animal per $\mathrm{d}$ in $42 \mathrm{~g}$ at $3.5 \mathrm{~g} /$ animal per $\mathrm{d})$ instead of water as done previously in the case of mothers. Both $\mathrm{BD}$ and $\mathrm{BD}+$ skimmed milk diets were divided into three equal parts, and each part was administered to BD, BD-MW and BD-MS + MW mice offspring, respectively, three times per $\mathrm{d}$, every $3-4 \mathrm{~h}$. For PFM feeding during the postweaning period, L. rhamnosus $\left(1 \times 10^{9} \mathrm{cfu} / \mathrm{ml}\right)$ fermented milk $(24 \mathrm{ml}$ at $2 \mathrm{ml} /$ animal per d) was lyophilised to half volume and equally supplied $\left(12 \times 10^{9} \mathrm{cfu}\right.$ in $\left.6.0 \mathrm{ml}\right)$ in glass plates to BD-PW and BD-PS + PW mice at $9.30 \mathrm{~h}$ (Indian Standard Time). After complete PFM consumption, mice were fed the $\mathrm{BD}$ as in control groups. Water was provided ad libitum at night and removed in the morning, 3-4 h before feeding the diets. The food bowls were also removed from the cages at night. These approaches were chosen to ensure the urge for food and water in the morning and complete food consumption. The supply of food/fermented milk in plates/bowls was preferred to oral intubation/cannula to avoid handling stress.

\section{Allergen sensitisation}

Based on the preliminary experiments to generate optimal allergen sensitisation, mice offspring of all the groups were sensitised with ovalbumin (OVA) $(20 \mu \mathrm{g}$ of OVA/animal with $2 \% \mathrm{Al}(\mathrm{OH})_{3}$ at a final volume of $150 \mu \mathrm{l}$ in PBS) through the intra-peritoneal route on day 21 of life just after weaning (Fig. 1(b)). The animals were subsequently sensitised twice through the intra-peritoneal route on weekly intervals along with oral challenge $(100 \mu \mathrm{g} /$ animal in $100 \mu \mathrm{l}$ PBS $)$ on alternate days after the second sensitisation ${ }^{(14)}$. The animals were euthanised on day 36 of life by diethyl ether overdose, and subsequently blood, spleen and intestines of each animal were collected to assess various immunological parameters.

\section{Physical assessment of allergic symptoms}

The acute allergen-specific skin response in mice offspring was measured before killing them ${ }^{(15)}$ on day 35 after $4 \mathrm{~h}$ of intra-peritoneal injection of the allergen. In brief, left ear pinnae of mice were injected with $10 \mu \mathrm{l}$ of PBS as control, whereas $10 \mu \mathrm{l}$ of allergen $(0.5 \mathrm{mg} / \mathrm{ml}$ OVA in PBS) was injected to the right pinnae. Ear thickness was measured using a digital micrometre (Aerospace Digital Caliper) at 0,1 and $2 \mathrm{~h}$ after injection. The allergen-specific net ear swelling $(\Delta \mathrm{mm})$ in the right ear was calculated by subtracting the basal thickness (at $0 \mathrm{~h}$ ) from the first and second hour thickness after challenge, which was further subtracted from the control (left ear) swelling measured 
(a)

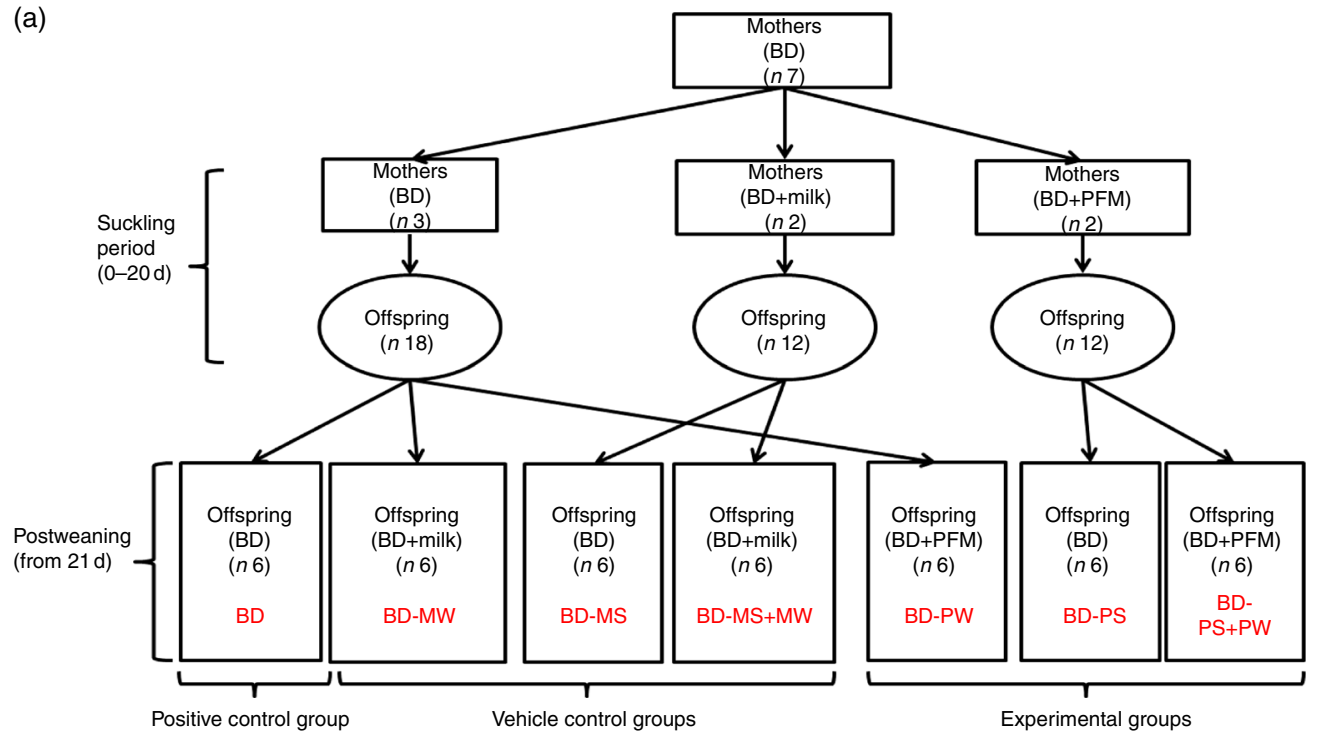

(b)

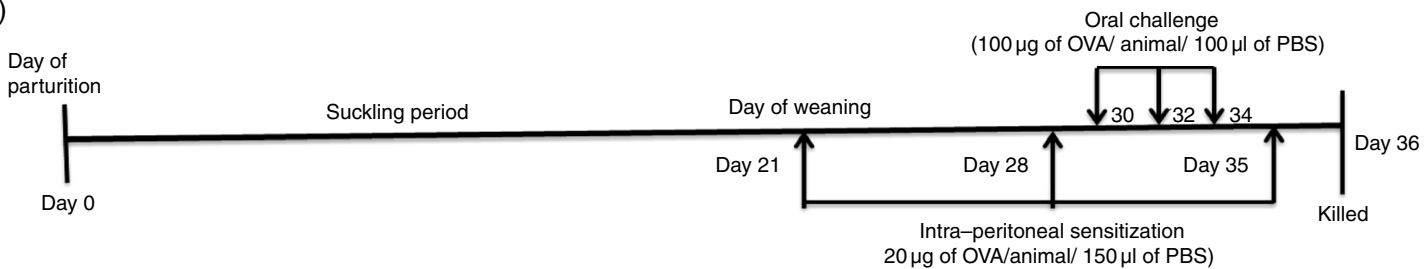

Fig. 1. Experimental design: (a) square boxes indicate the feeding to mothers in the suckling period (from $0-20 \mathrm{~d}$ ), round circles indicate number of offspring obtained from each main group. The offspring were divided into subgroups fed BD, BD supplemented with skimmed milk and BD supplemented with PFM after weaning (from day 21); (b) offspring were intra-peritoneally sensitised with allergen (ovalbumin (OVA)) on weekly intervals (days 21,28 and 35 ) and challenged orally on alternative days (days 30, 32 and 34) after the second (day 28) sensitisation. BD, Both mothers and offspring fed with basal diet during suckling and postweaning periods respectively; BDMW, mothers fed with basal diet during suckling period and offspring fed with basal diet supplemented with skimmed milk after weaning; BD-MS, mothers fed with basal diet supplemented with skimmed milk during suckling period while offspring fed with basal diet after weaning; BD-MS + MW, both mothers and offspring fed with basal diet supplemented with skimmed milk during sucking and postweaning periods respectively; BD-PW, mothers fed with basal diet during suckling period but offspring fed with basal diet supplemented with PFM after weaning; BD-PS, mother fed with basal diet supplemented with PFM during suckling period and offspring fed with basal diet after weaning; BD-PS + PW, both mothers and offspring fed with basal diet supplemented with PFM during suckling and postweaning periods respectively.

at the same time points. Moisture content in faecal samples as an indicator of diarrhoeal symptoms was also assessed by drying faecal samples in an incubator at $55^{\circ} \mathrm{C}$ for $24 \mathrm{~h}$. The faecal samples were collected on day 35 in the morning and afternoon hours by pressing the abdomen. Simultaneously, the body weight of newborns was recorded on the day of weaning (day 21) and just before they were killed on day 36.

\section{Tissue collection and sample preparation}

Blood was collected from the heart of animals by cardiac puncture, and after clotting it was centrifuged at $8000 \mathrm{rpm}$ for $10 \mathrm{~min}$ at $4^{\circ} \mathrm{C}$. The clear upper layer of serum was collected and stored in aliquots at $-20^{\circ} \mathrm{C}$ until further analysis. The intestinal fluid was drawn from the small intestine of mice ${ }^{(16)}$. Initially it was flushed with $5 \mathrm{ml}$ of PBS, followed by teasing with sterile needles in the same medium to separate the cells and was subsequently centrifuged at $2000 \mathrm{~g}$ for $30 \mathrm{~min}$ at $4^{\circ} \mathrm{C}$. The resultant supernatant - that is, the intestinal fluid - was recovered and stored at $-80^{\circ} \mathrm{C}$ until the immunological parameters were measured. Carefully collected spleen tissues were gently teased with sterile forceps to release splenocytes into RPMI
1640 medium. After removing large tissue clumps by sedimentation, the upper portion containing splenocytes was collected and centrifuged at $1800 \mathrm{~g}$ for $5 \mathrm{~min}$, followed by erythrocyte lyses $\left(0 \cdot 17 \mathrm{~m}\right.$-Tris- $\left.\mathrm{HCl}, 0 \cdot 16 \mathrm{~m}-\mathrm{NH}_{4} \mathrm{Cl}, \mathrm{pH} 7 \cdot 2\right)$ for $1 \mathrm{~min}$ and was subsequently washed twice with RPMI 1640 medium to remove all traces of lyses buffer. Finally, the cells were suspended into RPMI 1640 medium containing FCS (10\%), 2-mercaptoethanol (50 nm) and ConA $(5 \mu \mathrm{g} / \mathrm{ml}$ final concentration) and incubated at $37^{\circ} \mathrm{C}$ for $48 \mathrm{~h}$ in $\mathrm{CO}_{2}$ incubator perfused with $5 \% \mathrm{CO}_{2}$ in air, followed by centrifugation (1800 $\mathrm{g}$ for $5 \mathrm{~min}$ ) to collect the supernatant, which was stored at $-80^{\circ} \mathrm{C}$ until IL were estimated.

\section{Histological assessment of intestinal tissues}

Two centimetres of small intestinal tissue was used for the preparation of $3 \mu \mathrm{m}$ sections using Senior Rotary Microtome (Radical, RMT-30) $^{(17)}$. The histological slides were stained with haematoxylin and eosin stain for counting goblet cells and to determine villi morphology using an inverted light microscope (Olympus, CKX41). The unstained histological slides were prepared for direct immunofluorescence assay of $\operatorname{IgA}^{+}$cells ${ }^{(16)}$ 
using $\alpha$-chain mono-specific antibody (1:100 dilution) conjugated with fluorescein isothiocyanate (Cayman Chemical) and were observed under a fluorescent light microscope (CKX41; Olympus). The number of fluorescent cells was counted in thirty fields at $200 \times$ magnification. The results are expressed as the number of positive fluorescent cells per ten fields of vision.

\section{Assessment of humoral immune response}

Total serum antibodies. Total IgE and IgG antibodies in the serum were determined using quantitative sandwich ELISA (Komabiotech) kit. In brief, NUNC Maxisorp ninety-six-well plates were coated with $100 \mu \mathrm{l}$ of $1 \times$ capture antibody $(1 \mu \mathrm{g} / \mathrm{ml}$ of goat anti-mouse $\operatorname{IgE} / \operatorname{IgG}$ ) and incubated overnight at $4^{\circ} \mathrm{C}$. The samples (sixty-four and 200000 times diluted for IgE and IgG, respectively) were added to the experimental wells followed by the addition of $100 \mu \mathrm{l}$ of horseradish peroxidase (HRP)conjugated goat anti-mouse IgE or anti-mouse IgG. Plates were allowed to develop with the TMB (3,3,5,5,-tetramethyl diamine benzidine-containing $0.03 \% \mathrm{H}_{2} \mathrm{O}_{2}$ ), and the reaction was finally stopped with $50 \mu \mathrm{l}$ of $2 \mathrm{~N}-\mathrm{H}_{2} \mathrm{SO}_{4}$. The plates were read at $450 \mathrm{~nm}$ using an automated ELISA plate reader (Epoch BioTek). Total IgG1 and IgG2a antibodies in the serum were also determined in a quantitative sandwich ELISA format (eBiosciences) as described above using 6000 and 100 times diluted sera, respectively.

Estimation of allergen-specific antibodies. OVA-specific IgE, IgG and IgG1 were estimated by sandwich ELISA. In brief, plates were coated with $100 \mu \mathrm{l}$ of antigen $(100 \mu \mathrm{g} / \mathrm{ml}$ OVA $)$ in $0.06 \mathrm{M}$-carbonate buffer and incubated overnight at $37^{\circ} \mathrm{C} ; 100 \mu \mathrm{l}$ of $70 \%$ methanol was added to each well and incubated for $30 \mathrm{~min}$ to fix the antigen, followed by air drying for $10 \mathrm{~min}$. Free binding sites were blocked by adding $200 \mu \mathrm{l}$ blocking solution ( $1 \%$ bovine serum albumin in PBS) and incubated for $1 \mathrm{~h}$ at room temperature; $100 \mu \mathrm{l}$ of the diluted samples (IgE: four times; IgG: 600 times and IgG1: 100 times) were added to the respective wells and incubated for $1 \mathrm{~h}$ at $37^{\circ} \mathrm{C}$ with occasional shaking followed by the addition of $100 \mu \mathrm{l}$ of respective HRP-conjugated secondary antibodies. After $1 \mathrm{~h}$ incubation at $37^{\circ} \mathrm{C}$, the plates were allowed to develop with $100 \mu \mathrm{l}$ of TMB substrate, the reaction was stopped with $100 \mu \mathrm{l}$ of $2 \mathrm{~N}_{-} \mathrm{H}_{2} \mathrm{SO}_{4}$ and the absorbance was read at $450 \mathrm{~nm}$.

Cytokine response. The levels of IL in the supernatant of cultured splenocytes (interferon- $\gamma$ (IFN- $\gamma$ ), IL-4 and IL-10) and serum (tumour growth factor- $\beta$ (TGF- $\beta$ )) were estimated by using commercially available ELISA kits (eBioscience) according to manufacturer's protocol. In brief, ninety-six-well immune plates were coated with $100 \mu$ l of capture antibody (anti-mouse IFN- $\gamma$ / IL-4/IL-10/TGF- $\beta$ ) and incubated overnight at $4{ }^{\circ} \mathrm{C}$. The samples were diluted four times before adding them into the experimental wells followed by the addition of $100 \mu$ l biotin-conjugated detection antibody and avidin HRP conjugate, respectively. The plates were allowed to develop with the TMB, the reaction was stopped with $50 \mu \mathrm{l}$ of $2 \mathrm{~N}-\mathrm{H}_{2} \mathrm{SO}_{4}$ and the plates were read at $450 \mathrm{~nm}$.

The basal level of MCP-1 (as a marker of mucosal inflammation) and total sIgA levels were also analysed in the intestinal fluid using a quantitative sandwich ELISA kit (eBioscience and Komabiotech, respectively) as described above using two-times and 1000-times diluted samples, respectively.

Inflammatory gene expression. The tissues from murine intestines were teased with a needle in PBS and centrifuged at $2000 \mathrm{~g}$ for $20 \mathrm{~min}$ at $4^{\circ} \mathrm{C}$. The sediment (cells) was washed three times with PBS before being used for RNA extraction. Total RNA content was extracted using Tri Reagent (Sigma) according to the manufacturer's instructions. RNA concentration was quantified by NanoQuant (Tecan) and integrity was checked on $1.5 \%$ agarose. The RNA concentration was adjusted to $500 \mathrm{ng} / \mu \mathrm{l}$ for cDNA synthesis. One microgram of total RNA was reverse-transcribed by initiation at $65^{\circ} \mathrm{C}$ for $5 \mathrm{~min}$, followed by incubation at $42^{\circ} \mathrm{C}$ for $1 \mathrm{~h}$ in a $25 \mu \mathrm{l}$ mixture containing $200 \mathrm{U}$ RevertAid M-MuLV RT, 20 U RiboLock RNase inhibitor, $0.5 \mu \mathrm{g}$ oligo $(\mathrm{dT})_{18}$ primer, $4 \mu \mathrm{l} 5 \times$ reaction buffer and $0.8 \mathrm{~mm}-\mathrm{dNTP}$ mixture. The reaction was terminated at $70^{\circ} \mathrm{C}$ for $5 \mathrm{~min}$.

PCR was performed to amplify target genes cyclo-oxygenase- 2 (COX-2), toll-like receptor-2 (TLR-2) and TLR- 4 and the reference gene GAPDH of $81,199,201$, and $200 \mathrm{bp}$ length fragments, respectively, on Real-Time Thermocycler (7500 Fast-Real Time PCR, Applied Biosystems) with Light Cycler 480 SYBR Green master mix (Roche Diagnostics) using forward and reverse primers (online Supplementary Table S1).

Two microlitres of cDNA was used for the PCR in a final volume of $20 \mu \mathrm{l}$, containing $10 \mu \mathrm{l} 2 \times$ SYBER Green I master mix, $0 \cdot 2 \mu \mathrm{M}$ of each forward and reverse primers and $7 \cdot 2 \mu \mathrm{l}$ nuclease-free water. The PCR amplification was carried out using one cycle of initial denaturation at $94^{\circ} \mathrm{C}$ for $5 \mathrm{~min}$, thirty-five cycles of denaturation $\left(94^{\circ} \mathrm{C}\right.$ for $\left.30 \mathrm{~s}\right)$, annealing $\left(60^{\circ} \mathrm{C}\right.$ for $30 \mathrm{~s}$ ) and extension $\left(60^{\circ} \mathrm{C}\right.$ for $\left.45 \mathrm{~s}\right)$, with a final extension cycle at $60^{\circ} \mathrm{C}$ for $4 \mathrm{~min}$. After amplification, threshold $\left(C_{t}\right)$ values of both control and experimental groups with reference genes were used for calculating fold change in target gene expression.

\section{Statistical analyses}

Data were analysed using the Graph Pad Prism (version 5.01). Experimental results are mean values and their standard error of means. Data were subjected to one-way ANOVA, and the Tukey test was used to separate the means $(P<0.05)$ that were considered statistically significant.

\section{Results}

Effect of PFM on OVA-sensitised allergic symptoms

Varying degrees of allergen-specific skin responses were observed in the four control groups (BD, BD-MS, BD-MW and BD-MS + MW) of animals after $1 \mathrm{~h}$ and $2 \mathrm{~h}$ of intra-dermal challenge of ear pinna with OVA on day 35 before they were killed. However, murine offspring in PFM-fed groups (BD-PS, BD-PW and BD-PS + PW) showed significant decrease $(P<0.01)$ in ear swelling immediately after the first hour of allergen challenge. This effect became more pronounced $(P<0.001)$ after $2 \mathrm{~h}$ of challenge compared with $\mathrm{BD}$ and 
the three delivery vehicle control groups (BD-MS, BD-MW and BD-MS + MW) of mice (Fig. 2(a)). The supplementation of milk in the diet of mothers also showed $(P<0.05)$ a significant decrease in ear swelling compared with the BD group after $2 \mathrm{~h}$, but the effect was not as prominent as that in the probiotic groups. In this study, the diarrhoeal symptom was also visualised by discomfort behaviour in animals of the control groups along with watery stools. It was observed that the amount of water in stools decreased significantly $(P<0.05)$ in BD-PS and BD-PS + PW offspring where PFM was fed to mothers during the suckling period compared with the four types of control groups. However, it is notable that mice offspring provided with probiotics after weaning (BD-PW) did not show such changes in water content of faeces (Fig. 2(b)). On the other hand, no variations in body weight of newborns was initially observed up to the day of weaning (day 21), irrespective of the differences in feeding treatments, but later animals fed PFM during the suckling and postweaning periods (BD-PS + PW) showed significant $(P<0.01)$ body weight gain after $15 \mathrm{~d}$ of their rearing to the day 36 of life (Fig. 2(c)).

\section{Impact on intestinal histology and mucosal immune response}

The villi architecture in the control groups was observed to be severely distorted, whereas murine offspring exposed to PFM (BD-PS, BD-PW and BD-PS + PW) had well-defined, elongated and intact villi architecture (Fig. 3(a)). Likewise, the administration of PFM was significantly effective $(P<0.05)$ in increasing the population of goblet cells in offspring when their mothers were fed PFM (BD-PS and BD-PS+PW), which helped in shielding the surface of the intestinal epithelium by preventing the entry of various food-borne antigens through mucous secretion (Fig. 3(b)). The population of IgA + cells was significantly $(P<0.05)$ high in groups fed skimmed milk (BDMS and BD-MS + MW) and PFM (BD-PS and BD-PW) compared with BD control, but their number became remarkably
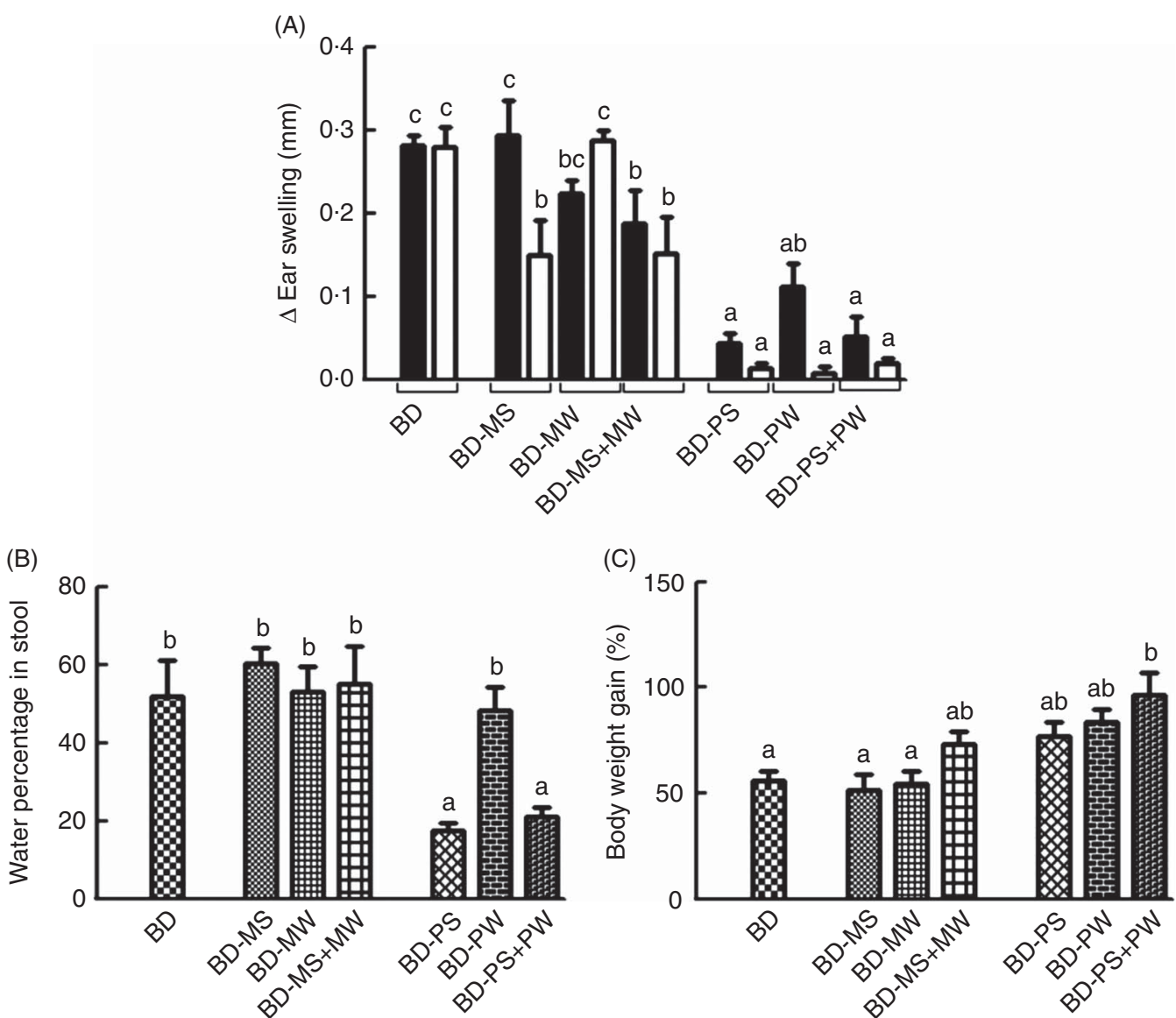

Fig. 2. Effect of feeding probiotic fermented milk (PFM) on physical symptoms of ovalbumin (OVA)-induced allergy: (A) change in ear pinna swelling at the first hour (dark bars) and second hour (light bars) of intra-dermal challenge with OVA; (B) water percentage in stools; and (C) percentage of body weight gain. Values are means with their standard error of means represented by vertical bars $(n \cdot 6) .{ }^{\text {a,b,c }}$ Different alphabets indicate the significant difference $(P<0 \cdot 05$; one-way ANOVA) among all the groups. BD, Both mothers and offspring fed with basal diet during suckling and postweaning periods respectively; BD-MW, mothers fed with basal diet during suckling period and offspring fed with basal diet supplemented with skimmed milk after weaning; BD-MS, mothers fed with basal diet supplemented with skimmed milk during suckling period while offspring fed with basal diet after weaning; BD-MS + MW, both mothers and offspring fed with basal diet supplemented with skimmed milk during sucking and postweaning periods respectively; BD-PW, mothers fed with basal diet during suckling period but offspring fed with basal diet supplemented with PFM after weaning; BD-PS, mother fed with basal diet supplemented with PFM during suckling period and offspring fed with basal diet after weaning; BD-PS + PW, both mothers and offspring fed with basal diet supplemented with PFM during suckling and postweaning periods respectively. $\square, 1$ st hour; $\square, 2$ nd hour. 
(A)

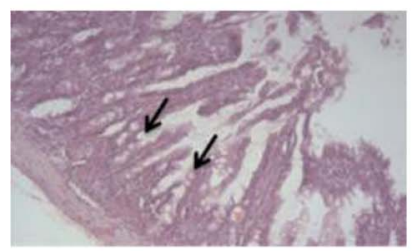

BD

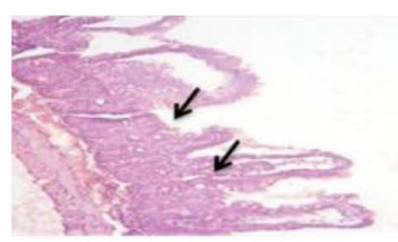

BD-MS

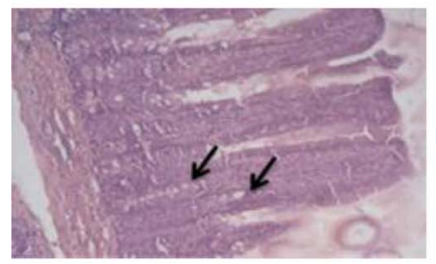

BD-PS

(C)

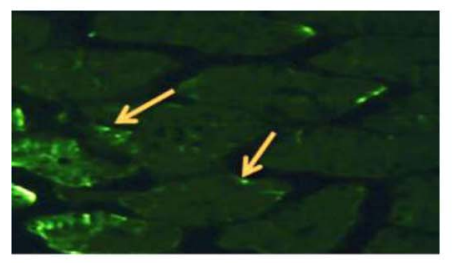

BD

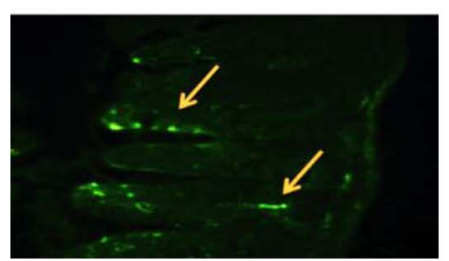

BD-MS

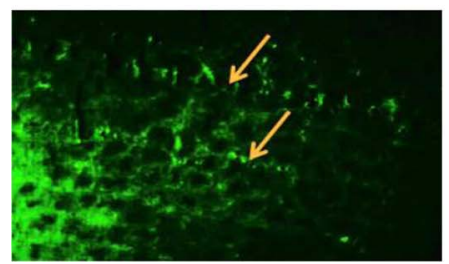

BD-PS

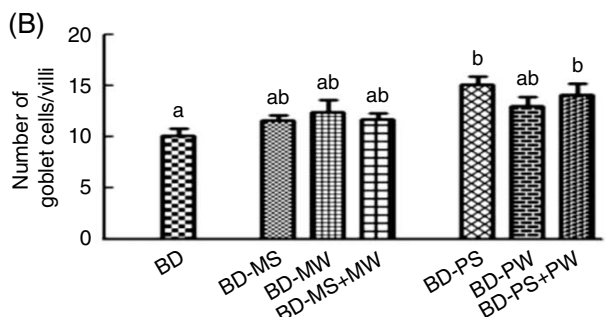

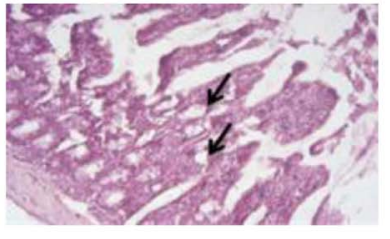

BD-MW

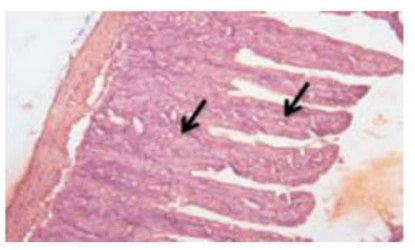

BD-PW

(D) 80
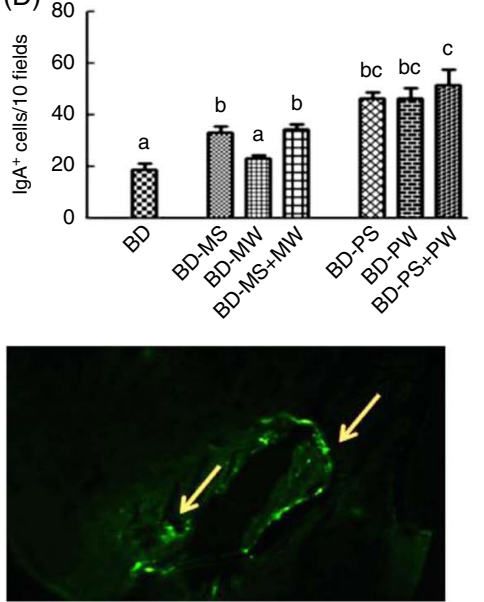

BD-MW

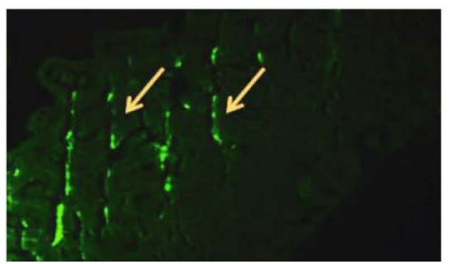

BD-PW

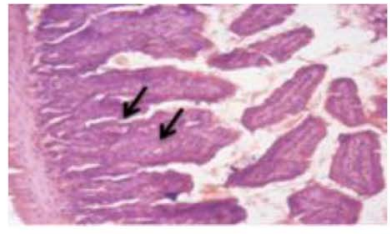

BD-MS+MW

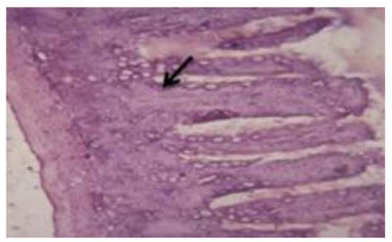

BD-PS+PW
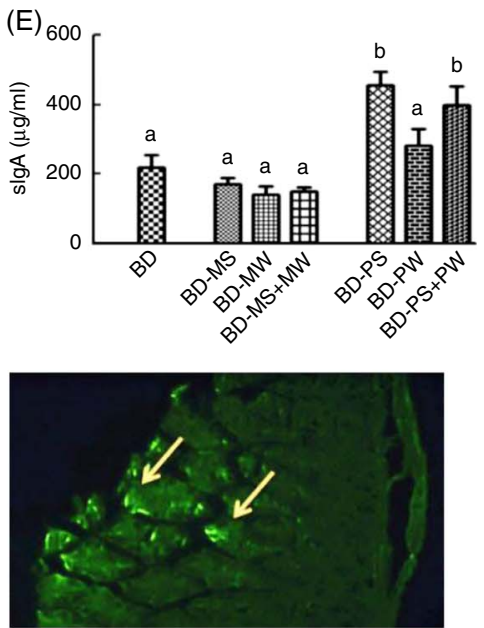

BD-MS+PW

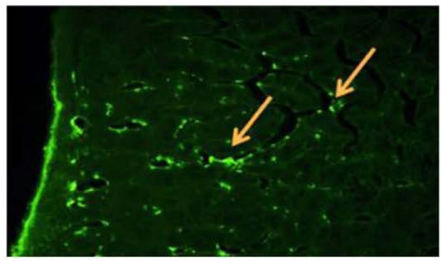

BD-PS+PW

Fig. 3. Effect of feeding PFM on intestinal histology after ovalbumin (OVA)-induced allergic sensitisation: (A) optical microscopy (200x) of intestinal villi morphology and goblet cells (arrows) in BD control, BD supplemented with skimmed milk (BD-MS, BD-MW, BD-MS + MW) and BD supplemented with probiotic fermented milk (PFM) (BDPS, BD-PW and BD-PS + PW); (B) number of goblet cells in the intestinal villi; (C) immunofluorescence $(200 \times)$ of IgA + cells in intestinal villi; (D) number of IgA + cells; and $(E)$ slgA levels in the intestinal fluid. Values are means with their standard error of means represented by vertical bars ( $n \cdot 6)$. ${ }^{a, b, c}$ Different alphabets indicate the significant difference $(P<0.05$; one-way ANOVA) among all the groups. BD, Both mothers and offspring fed with basal diet during suckling and postweaning periods respectively; BD-MW, mothers fed with basal diet during suckling period and offspring fed with basal diet supplemented with skimmed milk after weaning; BD-MS, mothers fed with basal diet supplemented with skimmed milk during suckling period while offspring fed with basal diet after weaning; BD-MS + MW, both mothers and offspring fed with basal diet supplemented with skimmed milk during sucking and postweaning periods respectively; BD-PW, mothers fed with basal diet during suckling period but offspring fed with basal diet supplemented with PFM after weaning; BD-PS, mother fed with basal diet supplemented with PFM during suckling period and offspring fed with basal diet after weaning; BD-PS + PW, both mothers and offspring fed with basal diet supplemented with PFM during suckling and postweaning periods respectively. 
$(P<0.001)$ more in animals fed PFM during suckling and postweaning periods (BD-PS + PW) (Fig. 3(c) and (d)). Similarly, intestinal sIgA levels (Fig. 3(e)) were more prominent $(P<0.01)$ in offspring groups (BD-PS and BD-PS + PW) where PFM was fed to mothers during the suckling period.

COX-2 is a key enzyme in prostaglandin synthesis during inflammation. In the present study, it was observed that the consumption of PFM by mothers and offspring during the suckling-weaning transition decreased $(P<0.05)$ the expression of COX-2 in the small intestine of newborns of the BD-PS, BDPW and BD-PS + PW groups (Fig. 4(a)) compared with the control (BD and BD-MW) groups. However, it is also interesting to note that supplementation of milk in the diets of mothers during the suckling period (BD-MS and BD-MS $+\mathrm{MW}$ ) reduced the expression of this inflammation-associated gene, which is quite similar to the probiotic-fed groups. In the case of TLR, significant increase $(P<0.05)$ in TLR-2 expression was observed in the probiotic-fed groups (BD-PS, BD-PW and BD-PS + PW) compared with the control groups, without any variation in the expression of TLR-4 (Fig. 4(b) and (c)). The present study also revealed that offspring of PFM-supplemented mothers (BD-PS and BD-PS + PW) showed significantly reduced $(P<0 \cdot 05)$ levels of MCP-1 compared with all four types of control groups (Fig. 4 (d)). However, no such changes were determined in the intestinal fluid of animals where diet containing L. rhamnosus fermented milk was fed only during the weaning period (BD-PW). Moreover, the levels of this inflammatory marker were much higher $(P<0.05)$ in the BD-MW group than in the rest of the groups.

\section{Humoral immune response}

Feeding of PFM during suckling (BD-PS), after weaning (BD-PW) or during both periods (BD-PS + PW) decreased total serum IgE levels remarkably $(P<0.001)$ compared with BD and all vehicle control groups (Fig. 5(a)). These results were further confirmed with the assessment of OVA-specific serum IgE levels, which also reduced considerably $(P<0.01)$ in BD-PS and BD-PS + PW than in control groups (Fig. 5(d)). On the other hand, no clear statistical variations were observed in total serum IgG levels between the control and the experimental groups, except for the animals in the BD-MW group $(P<0 \cdot 01)$ where skimmed milk was supplemented in the diet of offspring only during the postweaning period (Fig. 5(b)). Likewise, no specific
(A)

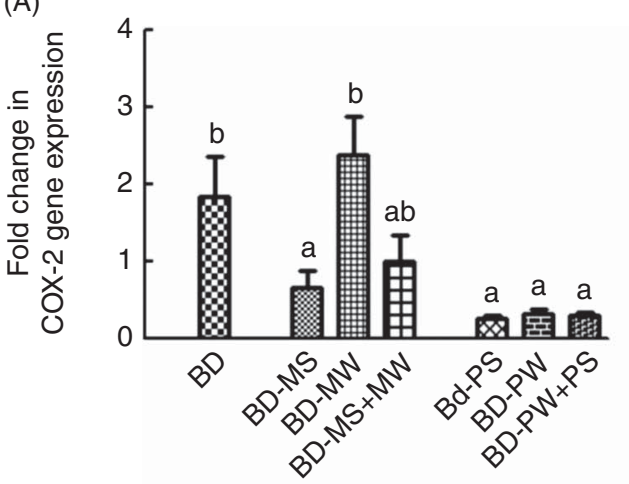

(B)

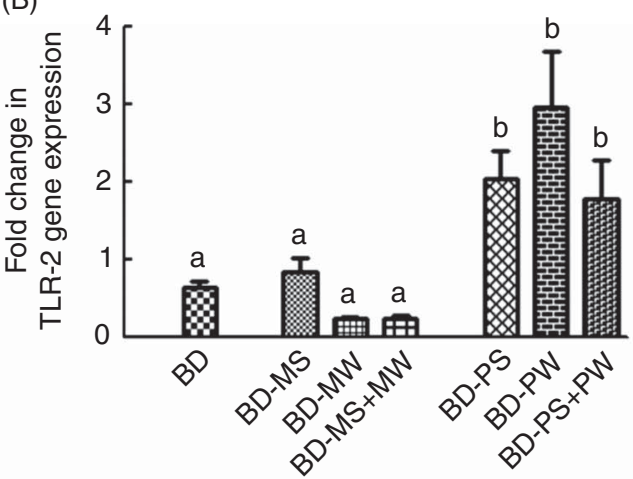

(D)

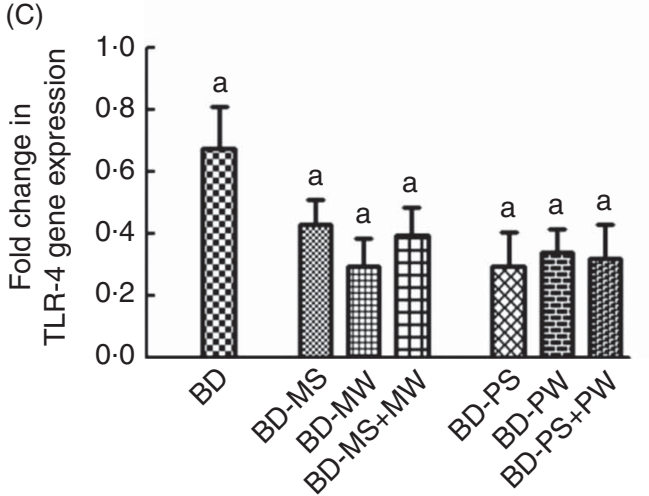

Fig. 4. Effect of feeding probiotic fermented milk (PFM) on the expression of inflammatory markers in the intestine after ovalbumin (OVA)-induced allergic sensitisation: (A) cyclo-oxygenase-2 (COX-2); (B) toll-like receptor-2 (TLR-2); (C) TLR-4; and (d) MCP-1. Values are means with their standard error of means represented by vertical bars (n-6). ${ }^{\mathrm{a}, \mathrm{b}, \mathrm{c}}$ Different alphabets indicate the significant difference $(P<0.05$; one-way ANOVA) among all the groups. BD, Both mothers and offspring fed with basal diet during suckling and postweaning periods respectively; BD-MW, mothers fed with basal diet during suckling period and offspring fed with basal diet supplemented with skimmed milk after weaning; BD-MS, mothers fed with basal diet supplemented with skimmed milk during suckling period while offspring fed with basal diet after weaning; BD-MS $+\mathrm{MW}$, both mothers and offspring fed with basal diet supplemented with skimmed milk during sucking and postweaning periods respectively; BD-PW, mothers fed with basal diet during suckling period but offspring fed with basal diet supplemented with $\mathrm{PFM}$ after weaning; BD-PS, mother fed with basal diet supplemented with PFM during suckling period and offspring fed with basal diet after weaning; BD-PS + PW, both mothers and offspring fed with basal diet supplemented with PFM during suckling and postweaning periods respectively. 
(A)

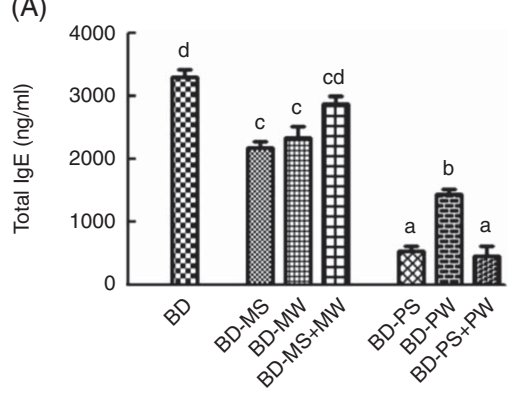

(D)

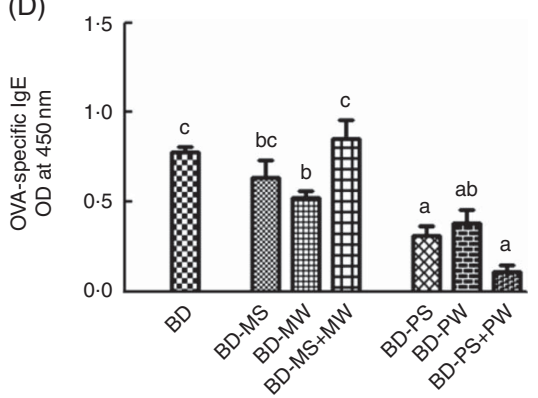

(B)

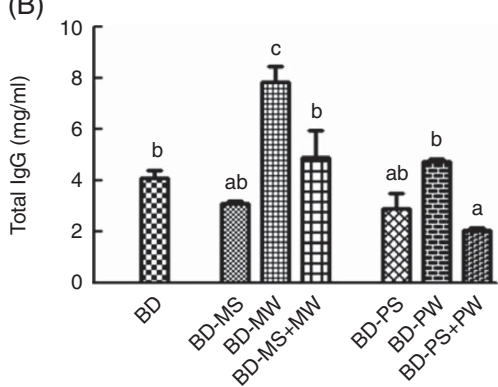

(E)
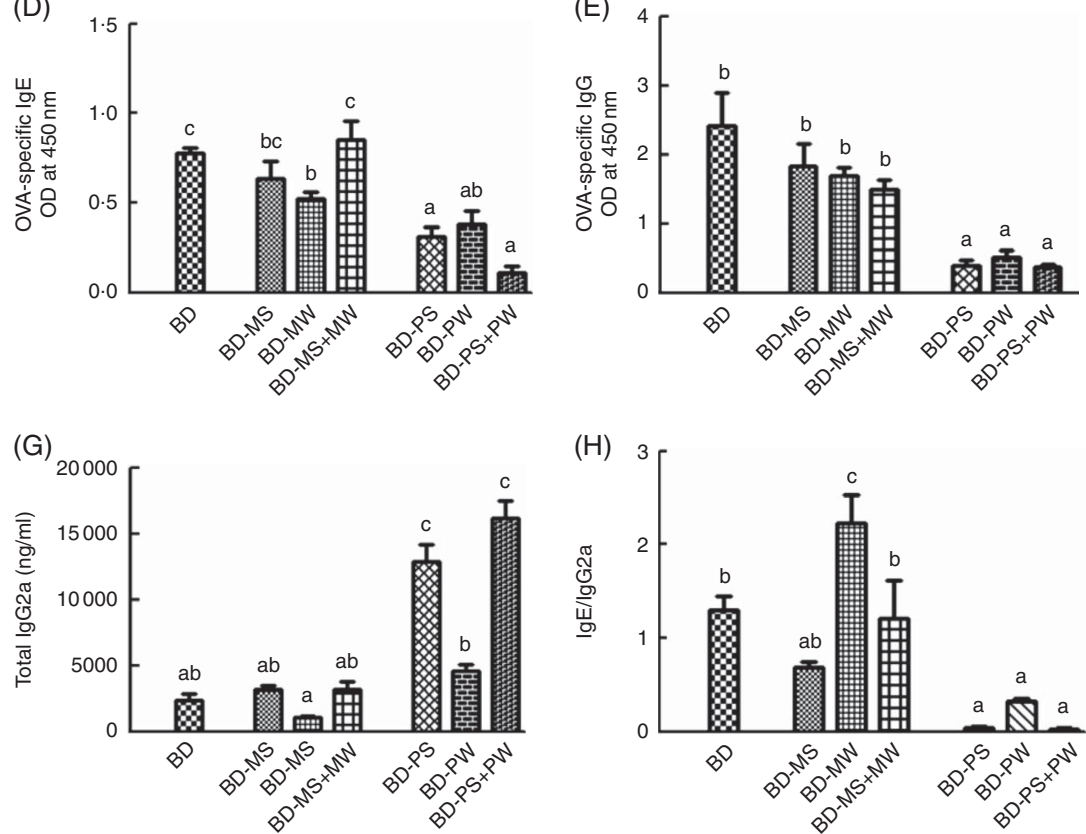

(H) 3

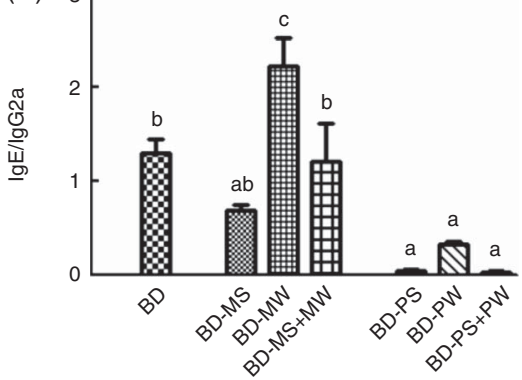

(C)

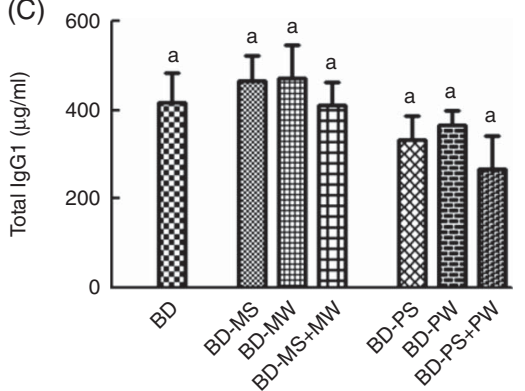

(F)

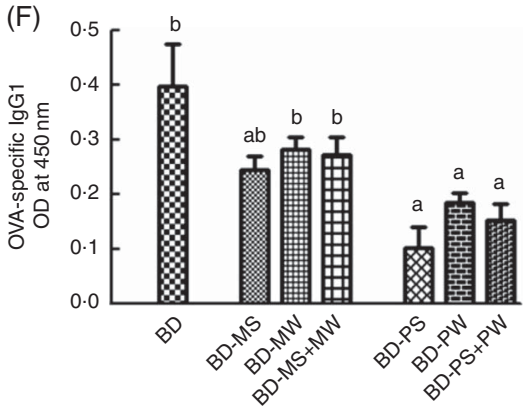

(l)

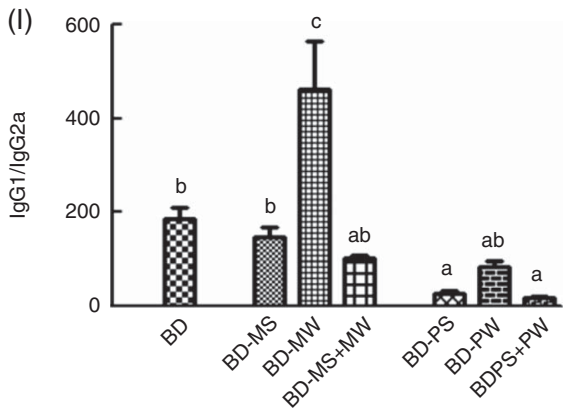

Fig. 5. Effect of feeding probiotic fermented milk (PFM) on humoral immune response in the serum after ovalbumin (OVA)-induced allergic sensitisation: (A) total IgE; (B) total IgG; (C) total IgG1; (D) OVA-lgE; (E) OVA-lgG; (F) OVA-lgG1, (G) total IgG2a; (H) IgE/lgG2a; and (I) IgG1/lgG2a. Values are means with their standard error of means represented by vertical bars $(n \cdot 6)$. ${ }^{\text {a,b,c }}$ Different alphabets indicate the significant difference $(P<0.05$; one-way ANOVA) among all the groups. BD, Both mothers and offspring fed with basal diet during suckling and postweaning periods respectively; BD-MW, mothers fed with basal diet during suckling period and offspring fed with basal diet supplemented with skimmed milk after weaning; BD-MS, mothers fed with basal diet supplemented with skimmed milk during suckling period while offspring fed with basal diet after weaning; BD-MS + MW, both mothers and offspring fed with basal diet supplemented with skimmed milk during sucking and postweaning periods respectively; BD-PW, mothers fed with basal diet during suckling period but offspring fed with basal diet supplemented with PFM after weaning; BD-PS, mother fed with basal diet supplemented with PFM during suckling period and offspring fed with basal diet after weaning; BD-PS + PW, both mothers and offspring fed with basal diet supplemented with PFM during suckling and postweaning periods respectively.

changes were recorded in the amount of total serum IgG1 among all feeding groups (Fig. 5(c)). However, it is interesting to note that OVA-specific levels of both IgG and IgG1 decreased considerably on feeding PFM in the diet of either offspring (BD-PW)/mothers (BD-PS) or both (BD-PS + PW) during the suckling and postweaning periods (Fig. 5(e) and (f)). Contrary to the above observations, feeding PFM to mothers during the suckling period (BD-PS and BD-PS + PW) remarkably increased the levels $(P<0.001)$ of total serum IgG2a (Fig. 5 (g)) compared with $\mathrm{BD}$ and delivery vehicle controls, despite the fact that no such changes were recorded when the probiotic was fed only to the weanlings (BD-PW). The above results of antibody responses can best be summarised by determining the ratio of $\operatorname{IgE} / \operatorname{IgG} 2 \mathrm{a}$ and $\operatorname{IgG} 1 / \operatorname{IgG} 2 \mathrm{a}$, which have also shown significantly reduced values after feeding PFM during suckingweaning transition (Fig. 5(h) and (i)). Nevertheless, a substantial increase $(P<0.05)$ in the ratio of IgE/IgG2a and IgG1/IgG2a in the BD-MW control group is quite notable (online Supplementary Table S2, showing levels of serum antibodies in the negative-control group).

\section{Cytokine response}

The estimated levels of cytokines in the splenocyte culture supernatant revealed a notable increase $(P<0 \cdot 001)$ in IFN- $\gamma$ (Th1 cytokine) in mice offspring (BD-PS and BD-PS + PW) on feeding mothers PFM during the suckling period compared with different control groups (Fig. 6(a)). In contrast to the above, a remarkable decrease $(P<0.01)$ in IL-4, belonging to Th2 pathway, was observed in both these groups. However, such changes were not recorded on feeding probiotic L. rhamnosus fermented milk to weanlings (BD-PW), only where levels were quite comparable 

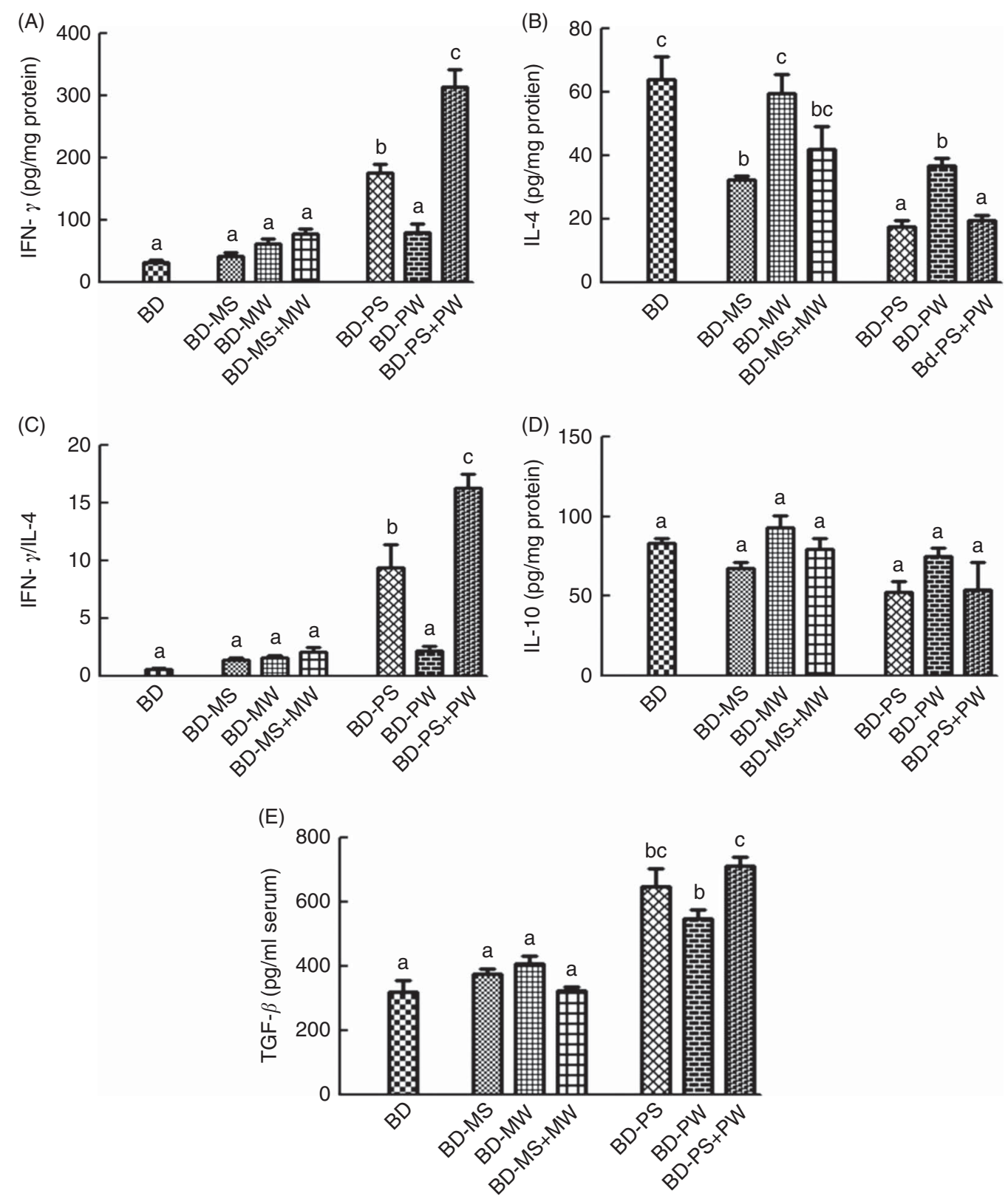

Fig. 6. Effect of feeding probiotic fermented milk (PFM) on cytokine release into the spleenocyte culture supernatant after ovalbumin (OVA)-induced allergic sensitisation: (A) interferon- $\gamma$ (IFN- $\gamma$ ); (B) IL-4; (C) IFN- $\gamma /$ IL-4; (D) IL-10; and (E) circulatory tumour growth factor- $\beta$ (TGF- $\beta$ ) levels (in serum). Values are means with their standard error of means represented by vertical bars $(n \cdot 6)$. ${ }^{\mathrm{a}, \mathrm{b}, \mathrm{c}}$ Different alphabets indicate the significant difference $(P<0.05$; one-way ANOVA) among all the groups. BD, Both mothers and offspring fed with basal diet during suckling and postweaning periods respectively; BD-MW, mothers fed with basal diet during suckling period and offspring fed with basal diet supplemented with skimmed milk after weaning; BD-MS, mothers fed with basal diet supplemented with skimmed milk during suckling period while offspring fed with basal diet after weaning; BD-MS + MW, both mothers and offspring fed with basal diet supplemented with skimmed milk during sucking and postweaning periods respectively; BD-PW, mothers fed with basal diet during suckling period but offspring fed with basal diet supplemented with PFM after weaning; BD-PS, mother fed with basal diet supplemented with PFM during suckling period and offspring fed with basal diet after weaning; BD-PS + PW, both mothers and offspring fed with basal diet supplemented with PFM during suckling and postweaning periods respectively.

with the delivery vehicle control groups (Fig. 6(b)). This shift in the cytokine profile towards the Th1 pathway on feeding probiotics during the suckling period (BD-PS and BD-PS + PW) was further established more clearly by considering the ratio of IFN- $\gamma$ / IL- 4 as depicted in Fig. 6(c). On the other hand, regulatory cytokines - namely, TGF- $\beta$ (Fig. 6(e)) - showed remarkably $(P<0.001)$ higher circulatory levels in the serum of mice from the probiotic-fed groups (BD-PS, BD-PW and BD-PS + PW) than in control groups, despite of the fact that no such changes occurred in splenocyte IL-10 levels (Fig. 6(d)) (online Supplementary Table S2 showing levels of cytokines in the negative-control group).

\section{Discussion}

The neonatal period is critical for vertebrate immune system development. In the present study, the administration of 
probiotic L. rhamnosus (MTCC 5897) fermented milk either to the mothers during the suckling period (BD-MS) or to the offspring (BD-PW) after weaning individually, otherwise successively (BD-PS + PW), appeared effective in the development of immune homoeostasis by counteracting allergen (OVA)-specific sensitisation compared with BD and skimmed milk-based delivery vehicle controls. Nevertheless, the results have shown more pronounced effects when mothers were fed PFM during the suckling period (BD-PS and BD-PS + PW) than individually to offspring during the postweaning period (BD-PW). These findings also clearly establish the alleviation of OVA-induced allergen sensitisation of the newborn's immune system in a holistic manner through a series of tests ranging from determination of physical symptoms by ear swelling data and water content in faeces to intestinal histology with mucosal immune response, which have been further substantiated with humoral and cytokine responses.

The allergen-induced ear pinna swelling method used in the present study has been considered as a new tool for determining systemic sensitisation to allergens in mice, which was previously deliberated equivalent to the skin-prick test ${ }^{(15)}$. The validity of this tool as a test for systemic sensitisation has been proved again during the course of this study, where remarkably higher levels of OVA-specific IgE and IgG1 in the positive control (BD) group were determined along with induction of ear swelling by OVA challenge. The acute ear swelling in mice would be triggered by high IgE levels, which has been generally known to play a crucial role in mast cell activation and degranulation ${ }^{(18)}$. Similarly, the presence of higher content of water in stool of mice from the control groups is also suggestive of diarrhoea, which is among the most prominent symptom of food allergy ${ }^{(19)}$. Likewise, severely distorted and damaged architecture of intestinal villi on induction of OVA-mediated allergic sensitisation in control groups could be rationalised to significant accumulation of lymphocytes in villus micro vessels and Peyer's patches of the small intestine causing atrophy and increased crypt complexity ${ }^{(20,21)}$.

In the present study, probiotic administration to mothers during the suckling period substantially contributed against allergen sensitisation in newborn mice by effectively reducing not only the visual allergic symptoms but also significantly increasing $\operatorname{sgA}, \operatorname{IgA}+$ cells and goblet cells in the intestine. Secretory IgA and mucus-producing goblet cells play a crucial role in immunity and mucosal homoeostasis of the gut by promoting the clearance of antigens Via their entrapment in mucus and later facilitating their removal from the intestinal lumen by peristalsis ${ }^{(22)}$. Evidences suggest that allergic reactions are related to retarded development of IgA-producing cells or insufficient sIgA-dependent function of the intestinal surface barrier $^{(23)}$. Previous studies have shown that feeding probiotic Lactobacillus casei DN-114001 fermented milk to the mothers during the suckling period and subsequently to their offspring after weaning not only increased sIgA and $\operatorname{IgA}+$ cells but also augmented the development of intestinal microbiota of newborn mice, thus indicating the role of probiotic treatment in improvement of mothers' immunity as well as passively protecting their pups' mucosal immune system ${ }^{(24)}$. There is a possibility that suckling mothers pass on maternal sIgA antibodies to the gut of the newborn through feeding milk, which may guide the uptake of corresponding dietary allergen/ antigen Via receptors for IgA present on $\mathrm{M}$ cell membranes of the Peyer's patch and provide relevant stimulation to the offspring immune system ${ }^{(23)}$. Earlier experiments in mice also showed the uptake of antigens that formed complexes with cognate maternal sIgA in the gut lumen of the newborn by the dendritic cells and carried them to mesenteric lymph nodes where homoeostatic immune response was generated through tolerance induction involving secretion of TGF- $\beta$ and IL-10 ${ }^{(25)}$.

Previously, we reported the restoration of Th1/Th2 immune homoeostasis in ageing mice by oral administration of L. rhamnosus (MTCC 5897) through aggressive increase in IFN- $\gamma$ and concurrent decrease in IL- 4 and IL- $10^{(13)}$. L. rhamnosus CRL 1505 has also been found to improve Th1 response by triggering TLR-2 signalling with augmented expression of IFN- $\gamma$ in porcine intestinal APCs and swine Peyer's patches ${ }^{(26)}$. TLR-2 was proved to be responsible for the recognition of gram-positive lactobacilli (probiotic bacteria: Lactobacillus acidophilus CRL924 and Lactobacillus delbrueckii CRL423 and nonprobiotic bacteria: L. acidophilus CRL1462 and L. acidophilus A9) ${ }^{(27)}$, which up-regulated IFN- $\gamma$ in $\mathrm{APCs}^{(28)}$ and also stimulated the tight-junction proteins to safeguard the intestinal epithelial barrier functions ${ }^{(29,30)}$. Thus, this scenario proposes an effective reversal of immune response on probiotic feeding to mothers during the suckling period to Th1 response from otherwise prevalent Th2 response, and thereby augmenting Th1/Th2 homoeostasis in newborn mice. The driving force for this homoeostatic mechanism seems to be the microbial impact that conditions APCs and $\mathrm{T}$ cells for tolerance by balancing polarising cytokines induced Via pattern-recognition receptors such as TLRs ${ }^{(23)}$ and Treg cells ${ }^{(31)}$. This can be clearly visualised in the present study with significant increase in TLR- 2 and TGF- $\beta$. In the present study, the improvement in allergen-induced Th2-mediated response in probiotic-fed groups has further been confirmed with the reduction in COX-2 expression in the small intestine of newborns, as reported earlier by probiotic Escherichia coli Nissle 1917 and Bifidobacterium lactis, respectively ${ }^{(32,33)}$. COX-2 is a key enzyme involved in the release of inflammatory mediators such as prostaglandins at the site of inflammation during allergen stimulation in an IgE-dependent mechanism ${ }^{(34)}$. The effectiveness of L. rhamnosus has been validated additionally in offspring mice on feeding probiotics to mothers during the suckling period by notably reduced levels of MCP-1 in the intestinal fluid, which has been known to be induced by IL- 4 and TNF- $\alpha{ }^{(35)}$

Analysis of humoral response in conjunction with robust increase in Th1 cytokine response also revealed significant effects of probiotic consumption by modulating downstream Ig production. Decreased levels of OVA-specific IgG, IgE and IgG1 in the offspring on feeding L. rhamnosus either to mothers or their pups during the suckling or weaning periods, respectively, than control groups of allergen challenge, has also been related to reduced Th2 response. At the same time, explicit increase in total IgG2a levels on feeding mothers with this strain of probiotics can be linked with increased Th1 response. Earlier reduction of allergen-specific antibodies in adult mice by suppressed production of OVA-specific IgE and IgG1 was also established by 
the oral administration of probiotics ${ }^{(36)}$ Bifidobacterium bifidum and $L$. casei, respectively. The ratios of $\operatorname{IgG} 1 / \mathrm{IgG} 2 \mathrm{a}$ and $\mathrm{IgE} /$ IgG2a provided a much better scenario, where significantly reversed effects have been observed clearly on probiotic feeding compared with BD and vehicle control groups, which have prevalent Th2 response due to allergen sensitisation. $T$ cell cytokines are responsible for stimulating the class switching process in B cells. Th2 cytokines, IL- 4 in particular, are considered the main driving force for favouring IgG1 production and class switching to IgE in differentiating $\mathrm{B}$ cells ${ }^{(37)}$. On the other hand, Th1 cytokine IFN- $\gamma$ is responsible for the synthesis of IgG2a and IgA, which prevents class switching to $\operatorname{IgE}^{(38)}$. Thus, the apparent decrease in IgG1/IgG2a and IgE/IgG2a on supplementation with probiotics in the mother's diet may be directly attributed to the robust increase in $\mathrm{IFN}-\gamma / \mathrm{IL}-4$ ratio, which again signifies the shift of the immune system towards Th1 response and onset of Th1/Th2 homoeostasis along with increased circulatory levels of regulatory cytokines (TGF- $\beta$ ). In partial corroboration with the present investigation, newborn pigs pre-treated orally with probiotic Lactococcus lactis up to $35 \mathrm{~d}$ of age were protected against allergy sensitisation to ovomucoid with lower IgG1/IgG2 and $\mathrm{IgE} / \mathrm{IgG} 2$ ratios and lower concentrations of Th2 cytokine IL-4 ${ }^{(39)}$. Our results also support previous observations, where perinatal probiotic L. rhamnosus supplementation (2-5 weeks before delivery to pregnant women and up to 6 months to lactating mothers) resulted in high IFN- $\gamma$ levels in offspring blood with parallel increase in breast milk TGF- $\beta$ and IgA levels compared with the placebo-treated mothers ${ }^{(40)}$. Thus, probiotic feeding to suckling mothers before weaning have prominent effects on the allergen sensitisation in newborns.

It has also been interesting to discuss here about the increased ratio of IgE/IgG2a and IgG1/IgG2a along with much higher expressions of MCP-1 and COX-2 in the BD-MW group, where milk proteins appeared to sensitise the newborns to allergen when their mothers were not formerly exposed to milk proteins, as reported earlier by us ${ }^{(41)}$. This could be linked to the fact that on feeding milk proteins to mothers (BD-MS and BD-MS + MW) during the suckling period developed oral tolerance to milk proteins in mothers, which may be subsequently passively transferred to the offspring, and also resulted in reduction of allergen-associated inflammatory reactions compared with the BD-MW group. Likewise, it has been formerly established that offspring breast-fed from allergen (OVA)-sensitised mothers during lactation were more effective in the development of oral tolerance compared with neonate mice from the non-sensitised mothers by facilitated transfer of dietary antigens along with their specific Ig to the offspring $^{(42)}$. High proteolytic activity of L. rbamnosus (unpublished results) used in the present study can also be attributed to the effective hydrolysis of proteins ${ }^{(43)}$ during passage through the gut and ease allergen sensitisation additionally, which was proved earlier by complete disappearance of milk whey protein antigenicity using lactic acid bacteria $^{(44)}$. Thus, PFM prepared with L. rhamnosus (MTCC 5897) might work through number of immunomudulatory pathways in a collective manner involving improved gut mucosal immunity, humoral immune response and Th1/Th2 homoeostasis in alleviating allergic sensitisation to OVA.

\section{Conclusion}

Thus, these findings strongly suggest that the supplementation of probiotic (L. rhamnosus) fermented milk either to the mothers during the suckling period (BD-PS) exclusively or subsequently to their offspring during the postweaning (BDPS + PW) period effectively control the abnormal deviations in immune response due to allergen sensitisation during the suckling-weaning transition. It potentially includes reduction of gut permeability and systemic penetration of antigens by restoration of villi architecture, increased production of mucous and SIgA by goblet and IgA + cells, respectively, with modulation of pathogen-recognition receptors (TLR-2) and decreased expression of inflammatory markers (COX-2 and MCP-1) in the intestine. Further, reduction in fiery response to allergen is also attributed to shift in the cytokine profile from biased Th2 to Th1 or tolerance induction (TGF- $\beta$ ), which can be proved conclusively by the reduction in $\operatorname{IgE} / \operatorname{IgG} 2 \mathrm{a}$ and $\operatorname{IgG} 1 /$ IgG2a ratios in systemic circulation. Further, our findings clearly establish that feeding probiotics to mothers during the suckling period have more prominent results in offspring (BD-PS and BD-PS + PW) than to offspring alone (BD-PW) in the postweaning period and make the timing of such interventions quite crucial to avoid food allergy in the early stages of life.

\section{Acknowledgements}

The present study was performed with the financial support from the Department of Biotechnology (DBT), Government of India (grant number: BT/PR-14976/FNS/20/511/2010 dated 8 March 2011). The DBT had no role in the design, analysis or writing of this article.

The authors V. S and R. S. contributed to experiments, data collection and statistical analysis. R. K. and S. K. contributed to the conception of experiments, supervision, data analysis and writing.

There are no conflicts of interest.

\section{Supplementary material}

For supplementary material/s referred to in this article, please visit http://dx.doi.org/doi:10.1017/S000711451500286X

\section{References}

1. Asher MI, Montefort S, Bjorksten B, et al. (2006) Worldwide time trends in the prevalence of symptoms of asthma, allergic rhinoconjunctivitis, and eczema in childhood: ISAAC phases one and three repeat multicountry cross-sectional surveys. Lancet 368, 733-743.

2. Helm RM \& Burks AW (2000) Mechanisms of food allergy. Curr Opin Immunol 12, 647-653.

3. Wegmann TG, Lin H, Guilbert L, et al. (1993) Bidirectional cytokine interactions in the maternal-fetal relationship: is successful pregnancy a Th2 phenomenon? Immunol Today 14, 353-356.

4. Sanders ME (2003) Probiotics: considerations for human health. Nutr Rev 61, 91-99.

5. Chapat L, Chemin K, Dubois B, et al. (2004) Lactobacillus casei reduces CD8 + T cell-mediated skin inflammation. Eur J Immunol 34, 2520-2528. 
6. Di Giacinto C, Marinaro M, Sanchez M, et al. (2005) Probiotics ameliorate recurrent Th1-mediated murine colitis by inducing IL-10 and IL-10-dependent TGF-beta bearing regulatory cells. J Immunol 174, 3237-3246.

7. Pohjavuori E, Viljanen M, Korpela R, et al. (2004) Lactobacillus GG effect in increasing IFN-gamma production in infants with cow's milk allergy. J Allergy Clin Immunol 114, 131-136.

8. Marschan E, Kuitunenw M, Kukkonenw K, et al. (2007) Probiotics in infancy induce protective immune profiles that are characteristic for chronic low-grade inflammation. Clin Exp Allergy 38, 611-618.

9. Sanz Y (2011) Gut microbiota and probiotics in maternal and infant health. Am J Clin Nutr 94, 2000S-2005S.

10. Azad MB, Coneys JG \& Kozyrskyj AL (2013) Probiotic supplementation during pregnancy or infancy for the prevention of asthma and wheeze: systematic review and meta-analysis. BMJ 347, f6471.

11. Kirjavainen PV, Arvola T, Salminen SJ, et al. (2002) Aberrant composition of gut microbiota of allergic infants: a target of bifidobacterial therapy at weaning? Gut 51, 51-55.

12. West CE, Hammarstrom ML \& Hernell O (2009) Probiotics during weaning reduce the incidence of eczema. Pediatr Allergy Immunol 20, 430-437.

13. Sharma R, Kapila R, Dass G, et al. (2014) Improvement in Th1/ Th2 immune homeostasis, antioxidative status and resistance to pathogenic E. coli on consumption of probiotic Lactobacillus rhamnosus fermented milk in aging mice. Age 36, 9686.

14. Lee BH, Cheng UH \& Wu SH (2013) Graptopetalum paraguayense ameliorates airway inflammation and allergy in ovalbumin-(OVA) sensitized BALB/C mice by inhibiting Th2 signal. Evid Based Complement Alternat Med 2013, 237096.

15. Bastiaan S, Betty CAM, Gerard AH, et al. (2008) Acute allergic skin reactions and intestinal contractility changes in mice orally sensitized against casein or whey. Int Arch Allergy Immunol 147, 125-134.

16. Raies MH, Kapila R \& Sliganti V (2014) Consumption of $\beta$-casomorphins- $7 / 5$ induce inflammatory immune response in mice gut through Th2 pathway. J Funct Foods 8, 150-160.

17. Kiernan JA (2008) Histological and Histochemical Methods Theory and Practice, 4th ed. Bloxham: Scion.

18. Amin K (2012) The role of mast cells in allergic inflammation. Respir Med 106, 9-14.

19. Furrie E (2005) Probiotics and allergy. Proc Nutr Soc 64, 465-469.

20. Ogawa T, Miura S, Tsuzuki Y, et al. (2004) Chronic allergy to dietary ovalbumin induces lymphocyte migration to rat small intestinal mucosa that is inhibited by MAdCAM-1. Am J Physiol Gastrointest Liver Physiol 286, G702-G710.

21. Song DJ, Cho JY, Miller M, et al. (2009) Anti-Siglec-F antibody inhibits oral egg allergen induced intestinal eosinophilic inflammation in a mouse model. Clin Immunol 131, 157-169.

22. Mantis NJ, Rol N \& Corthesy B (2011) Secretory IgA's complex roles in immunity and mucosal homeostasis in the gut. Mucosal Immunol 4, 603-611.

23. Brandtzaeg P (2010) Food allergy: separating the science from the mythology. Nat Rev Gastroenterol Hepatol 7, 380-400.

24. Moreno de Le Blanc A, Dogi CA, Galdeano CM, et al. (2008) Effect of the administration of a fermented milk containing Lactobacillus casei DN-114001 on intestinal microbiota and gut associated immune cells of nursing mice and after weaning until immune maturity. BMC Immunol 9, 27.

25. Corthesy B (2007) Roundtrip ticket for secretory IgA: role in mucosal homeostasis? I Immunol 178, 27-32.

26. Villena J, Chiba E, Vizoso-Pinto MG, et al. (2014) Immunobiotic Lactobacillus rhamnosus strains differentially modulate antiviral immune response in porcine intestinal epithelial and antigen presenting cells. BMC Microbiol 14, 126.
27. Dogi CA, Galdeano CM \& Perdigon G (2008) Gut immune stimulation by nonpathogenic gram (+) and gram (-) bacteria. Comparison with a probiotic strain. Cytokine 41, 223-231.

28. Castillo NA, de Moreno de LeBlanc A, Galdeano MC, et al. (2013) Comparative study of the protective capacity against Salmonella infection between probiotic and nonprobiotic lactobacilli. J Appl Microbiol 114, 861-876.

29. Cario E, Gerken G \& Podolsky DK (2004) Toll-like receptor 2 enhances ZO-1 associated intestinal epithelial barrier integrity via protein kinase C. Gastroenterol 127, 224-238.

30. Chen J, Rao JN, Zou T, et al. (2007) Polyamines are required for expression of Toll-like receptor 2 modulating intestinal epithelial barrier integrity. Am J Physiol Gastrointest Liver Physiol 293, G568-G576.

31. Sheil B, McCarthy J, Mahony L, et al. (2004) Is the mucosal route of administration essential for probiotic function? Subcutaneous administration is associated with attenuation of murine colitis and arthritis. Gut 53, 694-700.

32. Otte JM, Mahjurian-Namari R, Brand S, et al. (2009) Probiotics regulate the expression of COX-2 in intestinal epithelial cells. Nutr Cancer 61, 103-113.

33. Nurmi JT, Puolakkainen PA \& Rautonen NE (2005) Bifidobacterium Lactis sp. 420 up-regulates cyclooxygenase (Cox)-1 and down-regulates Cox-2 gene expression in a Caco- 2 cell culture model. Nutr Cancer 51, 83-92.

34. Chacon P, Vega A, Monteseirin J, et al. (2005) Induction of cyclooxygenase- 2 expression by allergens in lymphocytes from allergic patients. Eur J Immunol 35, 2313-2324.

35. Rollins BJ \& Pobert JS (1991) Interleukin-4 induces the synthesis and secretion of MCP-1/JE by human endothelial cells. Am J Pathol 138, 1315-1319.

36. Kim H, Kwack K, Kim DY, et al. (2005) Oral probiotic administration suppressed allergic responses in an ovalbumin induced allergy mouse model. FEMS Immunol Med Microbiol 45, 259-267.

37. Snapper CM, Finkelman FD \& Paul WE (1988) Differential regulation of IgG1 and IgE synthesis by interleukin 4. $J$ Exp Med 167, 183-196.

38. Le Bon A, Schiavoni G, Agostino G, et al. (2001) Type I interferons potently enhance humoral immunity and can promote isotype switching by stimulating dendritic cells in vivo. Immunity 14, 461-470.

39. Rupa P, Schmied J \& Wilkie BN (2011) Prophylaxis of experimentally induced ovomucoid allergy in neonatal pigs using Lactococcus lactis. Vet Immunol Immunopathol $\mathbf{1 4 0}$, 23-29.

40. Prescott SL, Wickens K, Westcott L, et al. (2008) Supplementation with Lactobacillus rhamnosus or Bifidobacterium lactis probiotics in pregnancy increases cord blood interferon gamma and breast milk transforming growth factor beta and immunoglobin A detection. Clin Exp Allergy 38, 1606-1614.

41. Kapila R, Kavadi PK \& Kapila S (2013) Comparative evaluation of allergic sensitization to milk proteins of cow, buffalo and goat. Small Ruminant Res 112, 191-198.

42. Yamamoto T, Tsubota Y, Kodama T, et al. (2012) Oral tolerance induced by transfer of food antigens via breast milk of allergic mothers prevents offspring from developing allergic symptoms in a mouse food allergy model. Clin Dev Immunol 2012, 721085 .

43. Kleber N, Weyrich U \& Hinrichs J (2006) Screening for lactic acid bacteria with potential to reduce antigenic response of $\beta$-lactoglobulin in bovine skim milk and sweet whey. Innov Food Sci Emer 7, 233-238.

44. Bu G, Luo Y, Zhang Y, et al. (2010) Effects of fermentation by lactic acid bacteria on the antigenicity of bovine whey proteins. J Sci Food Agric 90, 2015-2020. 